\title{
ASSESSMENT OF LANDSLIDE-INDUCED MORPHOLOGY CHANGES USING AN OBJECT-BASED IMAGE ANALYSIS APPROACH: A CASE STUDY OF HÍTARDALUR, ICELAND
}

\author{
Z. Dabiri ${ }^{1, *}$, D. Hölbling ${ }^{1}$, L. Abad ${ }^{1}$, D. Tiede ${ }^{1}$ \\ ${ }^{1}$ Department of Geoinformatics - Z_GIS, University of Salzburg, 5020 Salzburg, Austria- (zahra.dabiri, daniel.hoelbling, \\ lorenacristina.abadcrespo, dirk.tiede)@sbg.ac.at
}

KEY WORDS: Landslide, Earth Observation (EO), River System, Object-Based Image Analysis (OBIA), Sentinel-1, Iceland

\begin{abstract}
:
On July 7, 2018, a large landslide occurred at the eastern slope of the Fagraskógarfjall Mountain in Hítardalur valley in West Iceland. The landslide dammed the river, led to the formation of a lake and, consequently, to a change in the river course. The main focus of this research is to develop a knowledge-based expert system using an object-based image analysis (OBIA) approach for identifying morphology changes caused by the Hítardalur landslide. We use synthetic aperture radar (SAR) and optical remote sensing data, in particular from Sentinel-1/2 for detection of the landslide and its effects on the river system. We extracted and classified the landslide area, the landslide-dammed lake, other lakes and the river course using intensity information from S1 and spectral information from S2 in the object-based framework. Future research will focus on further developing this approach to support mapping and monitoring of the spatio-temporal dynamics of surface morphology in an object-based framework by combining SAR and optical data. The results can reveal details on the applicability of different remote sensing data for the spatio-temporal investigation of landslides, landslide-induced river course changes and lake formation and lead to a better understanding of the impact of large landslides on river systems.
\end{abstract}

\section{INTRODUCTION}

\subsection{Background}

Accurate mapping of landslides is an important element for hazard analysis. On July $7^{\text {th }} 2018$, a large landslide occurred on the eastern side of the Fagraskógarfjall mountain in the Hítardalur valley, west Iceland. The landslide blocked the river and led to the formation of a lake upstream (Helgason et al., 2019). According to the Icelandic Meteorological Office (IMO), the Fagraskógarfjall landslide is considered among the largest landslides in historical time in Iceland, with an estimated volume of 10-20 million cubic meters (Pétursson, 2018). Rapid mass movements are common geomorphological processes in Iceland and pose a significant risk to people and infrastructure (Sæmundsson et al., 2018).

Earth Observation (EO) data has great potential for mapping, monitoring and analysis of landslides, and particularly landslides and landslide-dammed lakes (Cigna, 2018). It can provide valuable information for rapid landslide mapping (Plank et al., 2016). Synthetic Aperture Radar (SAR) imagery, in particular, is an important source of information, together with optical satellite imagery, for hazard analysis (Joyce et al., 2009). Especially the combined interpretation of SAR and optical imagery offers valuable possibilities for landslide mapping, for example in emergency situations, while existing approaches still need to be improved (Hölbling et al., 2018).

In this study, we focus on using freely available Sentinel-1 (S1) SAR and Sentinel-2 (S2) optical imagery for mapping the Hitardalur landslide, and analysis of the changes in the river course.

The main objectives of this study are:

1. to explore the potential of SAR imagery for landslide mapping in conjunction with optical imagery within an object-based image analysis (OBIA) framework, and

2. to study changes in the river channel system in the Hítardalur valley after the landslide

\subsection{SAR for Landslide Mapping}

Accurate detection of land-surface changes is a key element for understanding processes and interactions between human and natural phenomena (Lu et al., 2004; Singh, 1989). SAR imagery has the potential to be used for hazard assessment, by providing large-scale two-dimensional (2D) high spatial resolution images of the Earth's surface (Lee and Pottier, 2009). Radar pulses can penetrate through clouds (nearly weather independent), and they can provide data during day and night (sun independent) (Jensen, 2015). According to Lee and Pottier (2009), the surface reflectivity measured by radar imagery (a.k.a.: radar backscatter coefficient $\sigma^{0}$ ) is a function of the radar system parameters (such as frequency, polarization, incident angle, etc.); and the surface parameters (such as topography, roughness, dielectric properties of the medium, moisture, etc.).

These parameters can be used to extract features from SAR imagery. Moreover, different polarizations provide different information about features of interest on the ground. Four polarizations are possible by combining horizontal $(\mathrm{H})$ and vertical $(\mathrm{V})$ polarized waves for sending and receiving antennas i.e. HH, HV, VV, and VH (Jensen, 2009). Depending on the structure and position of the feature of interest, it might appear differently when varying the polarization.

\subsection{Object-based Image Analysis}

Object-based image analysis (OBIA) has been used for more than two decades as a framework for feature extraction, especially from very high spatial resolution imagery (Blaschke et al., 2014; Chen et al., 2018). OBIA is highly suitable for combining different sources of information, such as spectral and textural features and the integration of spatial information during image segmentation and classification to complement and improve existing approaches for landslide mapping (Hölbling et al., 2017). With the increasing availability of SAR imagery, its integration in OBIA approaches for feature extraction is expanding within the literature (Casagli et al., 2016). 


\section{STUDY AREA AND DATA}

\subsection{Study Area}

The study area is in the Hítardalur valley at the eastern side of the Fagraskógarfjall mountain in West Iceland (Figure 1).
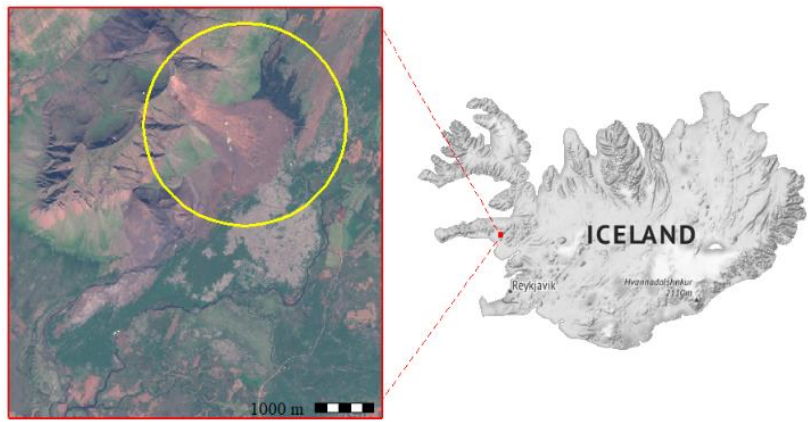

Figure 1. The study area is located at the eastern side of the of Fagraskógarfjall mountain, West Iceland. The yellow circle indicates the landslide location.

\subsection{Data}

The Sentinel missions, designed and developed by the ESA (European Space Agency), with its high temporal resolution provide very good opportunities for mapping and monitoring spatio-temporal dynamics of land surface morphology. Two data sets were used in this study: a) Sentinel-1 (S1), which provides SAR data and b) Sentinel-2 (S2), which provides optical imagery at high spatial resolution between 10 and 60 meters (Table 1).

S1 carries a C-band SAR instrument and obtains data in dual polarization such as $\mathrm{VH}$ and $\mathrm{VV}$, or $\mathrm{HH}$ and $\mathrm{HV}$. We used the Ground Range Detected High resolution (GRDH) S1 product for intensity analysis, including the Interferometric Wide (IW) swath mode included VH and VV polarization, and the Extra Wide (EW) swath mode included $\mathrm{HV}$ and $\mathrm{HH}$ polarization. Both modes were combined and used for feature classification based on the backscatter coefficient. In addition, we used a preand post-event S1 and S2 images for extracting the landslide, landslide-dammed lake, lakes and river course. Furthermore, we identified river course changes due to the landslide event.

\begin{tabular}{|l|c|c|c|}
\hline Date & $\begin{array}{c}\text { Sensor, Type, } \\
\text { Mode }\end{array}$ & Polarization & $\begin{array}{c}\text { Pre/Post } \\
\text { event }\end{array}$ \\
\hline $2018 / 07 / 05$ & S1-A, IW, GRDH & VH, VV & Pre \\
$2018 / 07 / 09$ & S1-B, IW, GRDM & VH, VV & Post \\
$2018 / 07 / 10$ & S1-A, EW, GRDH & HV, HH & Post \\
$2018 / 07 / 11$ & S1-A, IW, GRDH & VH, VV & Post \\
\hline Date & \multicolumn{2}{|c|}{ Sensor, Product } & $\begin{array}{c}\text { Pre/Post } \\
\text { event }\end{array}$ \\
\hline $2018 / 06 / 20$ & \multicolumn{2}{|c|}{ S2-B, MSI Level-1C } & Pre \\
$2018 / 07 / 17$ & \multicolumn{2}{|c|}{ S2-B, MSI Level-1C } & Post \\
\hline
\end{tabular}

Table 1. Sentinel-1(S1) and Sentinel-2 (S2) images used.

\section{METHODS}

\subsection{Pre-processing}

The pre-processing of S1 data was performed using the Sentinel Application Platform (SNAP) toolbox (Zuhlke et al., 2015). A spatial subset of the images was extracted within the study area to improve the computing efficiency. The overall pre-processing of the S1 data for intensity analysis included thermal noise removal, orbit file calibration, terrain correction, and DEMassisted co-registration.

For the S2 imagery, the gathering of the data and pre-processing was performed using Google Earth Engine. The cloud mask provided with Level $1 \mathrm{C}$ data was used to mask out clouds in both S2 images. The images were clipped to the study area and exported for further analysis.

\subsection{Change Detection}

According to Singh (1989), change detection is the process of identifying differences in the state of an object or phenomena by observing it at different times. Change detection is useful for disaster monitoring and damage assessments. The assumption is that changes on the Earth's surface must result in changes in radiance values of that particular media, hence, it must change the radiance reflected in the EO imagery. However, changes might happen due to several other parameters, such as differences in atmospheric conditions, difference in sun angle, and differences in soil moisture (Jenson, 1983). Therefore, the choice of the EO imagery on which the change detection will be applied is crucial. The change detection technique was based on a differencing method, meaning that one image (pre-event image) is subtracted from a second image (post-event image). The main challenge of such a method is deciding where to place the thresholds, and to establish where changes happened or not. In this research, change detection was done on a pixel level, between two pre (2018/07/05) and post (2018/07/11) S1 images. The change detection was performed using the SNAP toolbox. The following products were produced and imported to eCognition (Trimble) to conduct OBIA for feature extraction:

1. Change detection using VH polarization

2. Change detection using VV polarization

3. Combining four polarizations: $\mathrm{VV}, \mathrm{VH}, \mathrm{HV}, \mathrm{VV}$

4. S2 images, including pre- and post-event

\subsection{Object-based Image Analysis and Data Integration}

We used OBIA to semi-automatically extract the changed areas. Four classes were defined: 1) landslide, 2) landslide-dammed lake, and 3) river course, and 4) lakes. The overall framework included a multiresolution segmentation and a rule-based feature extraction and classification at the object level.

\section{RESULTS}

\subsection{Feature Extraction Using OBIA}

Table 2 shows the EO imagery ( 1 and S2) used for this study.

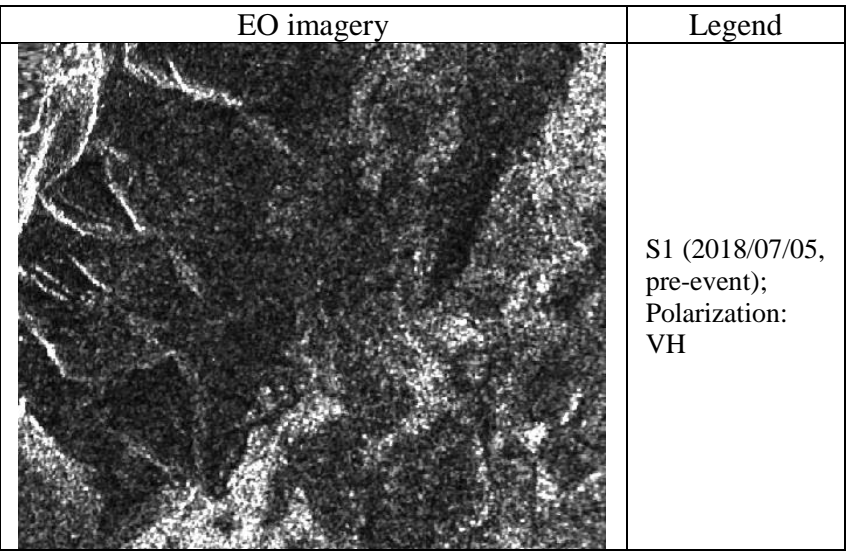




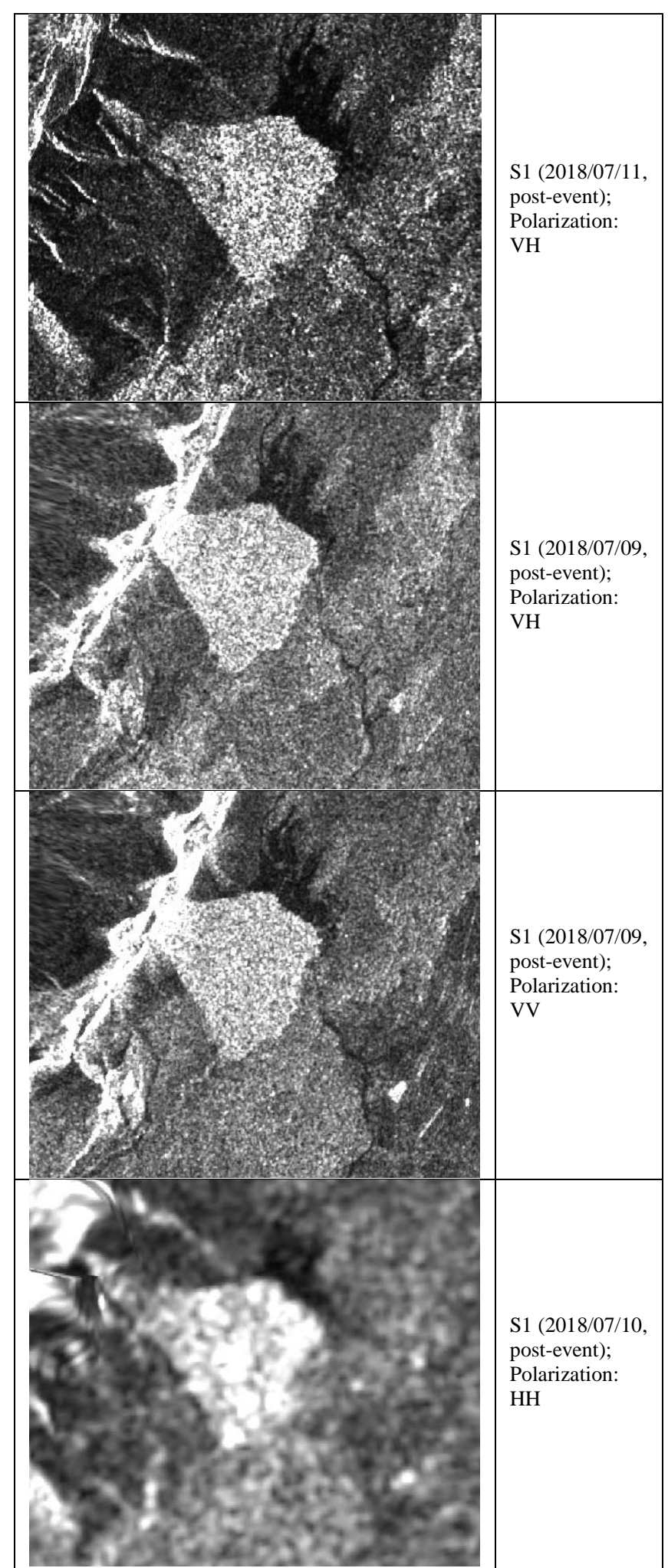

post-event);

Polarization $\mathrm{HH}$

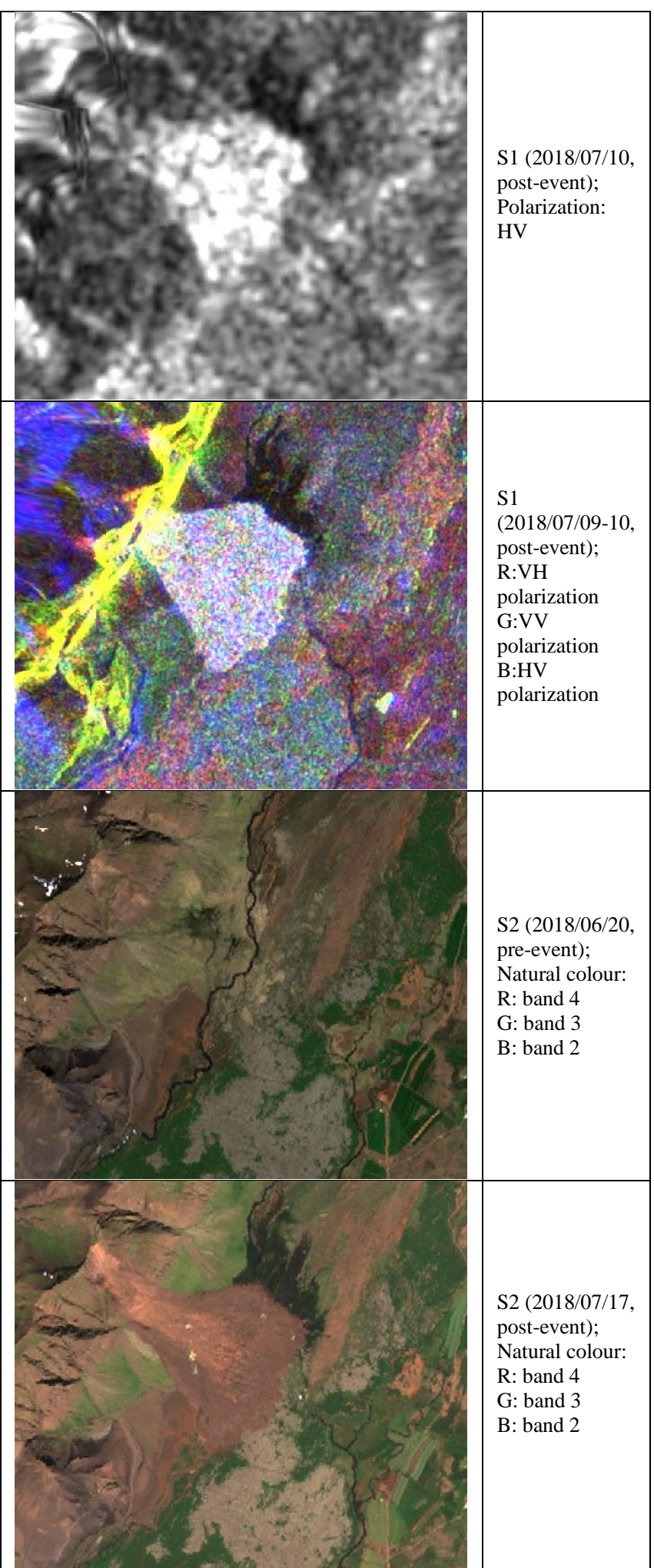

Table 2. The of S1 and S2 images used for change detection, and object-based classification.

In all post-event $\mathrm{S} 1$ images, the landslide is visually distinguishable from its surroundings due to its very bright appearance. In the S1 imagery, there is a bright area above the landslide (top of the mountainous area), which is caused by the foreshortening effect.

The open water body areas (such as a big lake in the lower left of the subset or the landslide-dammed lake in the upper right 
north of the landslide deposition area) appear very dark compared to their surroundings. The river course also appears dark. The four features of interest, i.e. landslide, landslidedammed lake, other lakes and the river course, were distinguished from each other using a $\mathrm{S} 1$ false colour composite (red: $\mathrm{VH}$, green: $\mathrm{VV}$, and blue: $\mathrm{HH}$ ).

Classification rules based on expert-knowledge were used to extract objects of interest from of the S1 imagery. The following procedure was applied:

1. Multiresolution segmentation

2. Feature extraction based on backscatter coefficient for landslide and lakes

3. Removing false positives based on area thresholds

4. Spatial relationships between lakes and landslide was used to classify landslide-dammed lake

We used the S2 pre-event image to extract the river course. The multiresolution segmentation was applied on the S2 image, whereby the segmentation parameters were tuned by an expert guided trial and error approach. The class river course was classified in the OBIA framework using knowledge-based classification rules.

Figure 2 illustrates the results of the object classification using combined multi-polarization S1 images and the pre-event S2 image. The landslide and the lakes were classified using S1 imagery, and the river course was classified using the S2 preevent image.

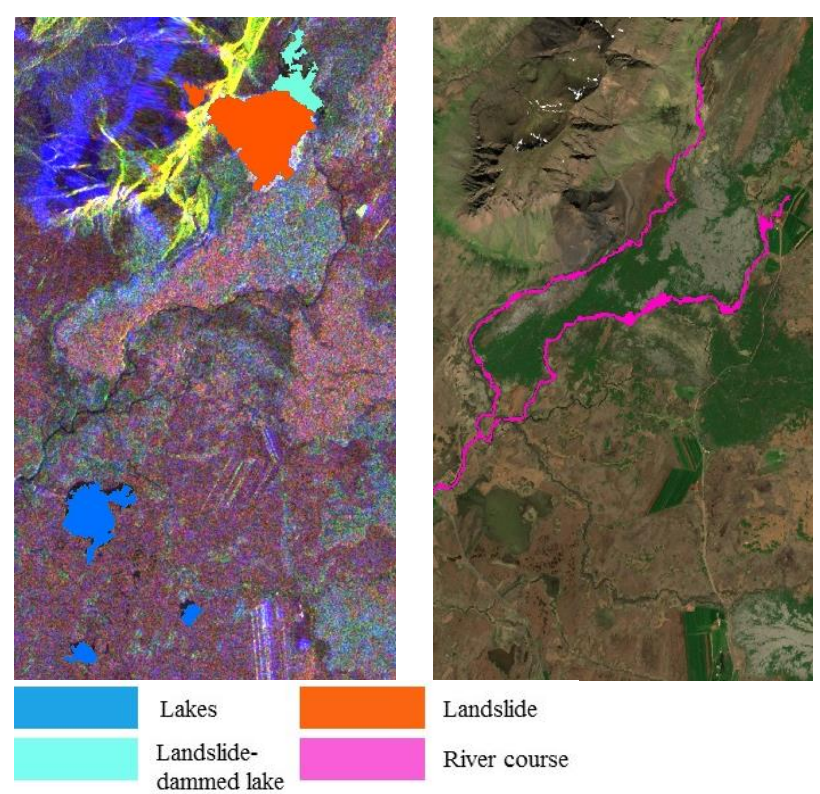

Figure 2. Classification results using S1 and S2 imagery, showing the following classes: Landslide-dammed lake, landslide, lakes, river course.

\subsection{Change Detection Using Different Polarimetry}

The second objective of this study was to explore the effect of different polarizations for the analysis of changes, specifically the case of a landslide event and the subsequent creation of a landslide-dammed lake.

We used two S1 images, the pre-event image from 2018/07/05, and the post-event image from 2018/07/11. We used a rulebased image classification approach for $\mathrm{VH}$ and $\mathrm{VV}$ polarizations (Figure 3). The change detection included 1) a multiresolution segmentation, and 2) the use of classification thresholds based on the objects mean values for each polarization.
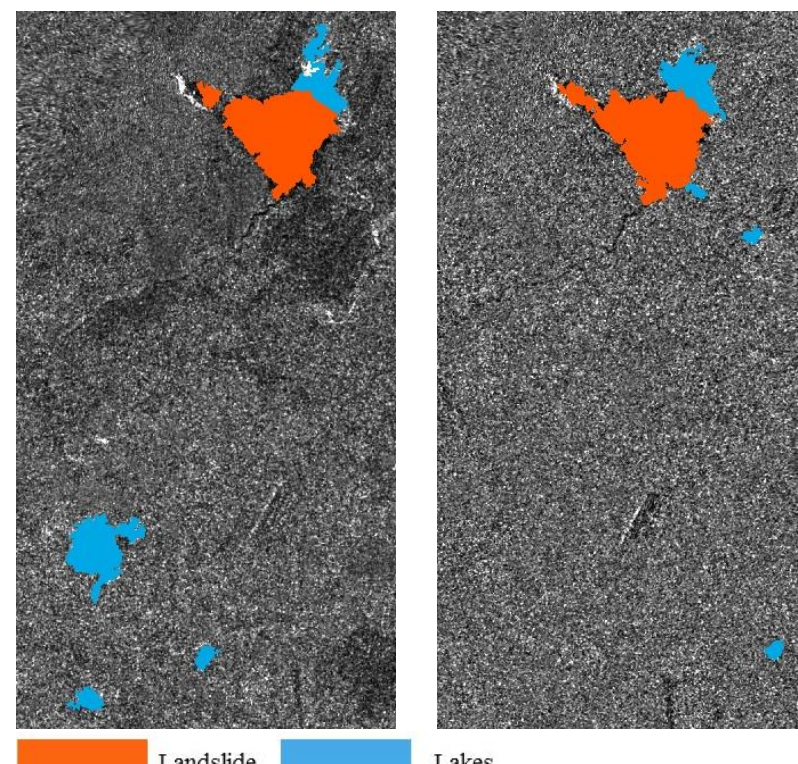

Lakes

Figure 3. Results of the feature extraction from change detection products for two polarizations: a) $\mathrm{VV}$ and b) $\mathrm{VH}$.

Finally, we used the symmetrical difference between the class landslide and the class river course and measured the length of $1.897 \mathrm{~km}$ for the old river course which was fully covered by the landslide. We used the S2 pre- and post-event change detection product and measured $4.663 \mathrm{~km}$ for the length of the old river bed where no water is running anymore due to the diversion of the river water.

The area covered by the landslide-dammed lake was measured about 48 ha and the area covered by the landslide was measured about 170 ha (Figure 4).

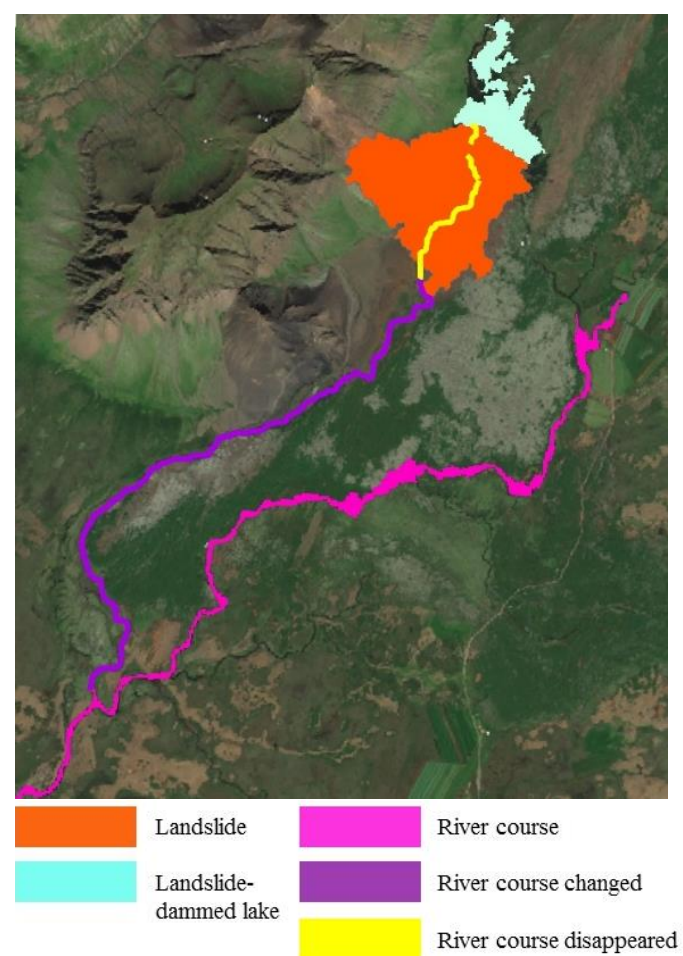

Figure 4. The final classifications result based on S1 and S2 imagery. 


\subsection{Validation}

According to Helgason et al. (2019), the landslide-dammed lake was $\sim 47$ ha, and the debris covers approximately 150 ha. According to our analysis the area covered by the landslidedammed lake is approximately $48 \mathrm{ha}$, and the landslide area is about 170 ha. As shown in Figure 4 the new river course was not completely classified using this approach. This might relate to the setting of the multiresolution segmentation and that the resulting objects do not meet the classification thresholds.

\section{DISCUSSION}

In this study, we investigated the Hitardalur landslide and its impact on the river system based on pre- and post-event EO data. We used S1 and a combination of different polarizations, and created change detection products for $\mathrm{VV}$ and $\mathrm{VH}$ polarizations. The object-based classification was done based on rule-based and expert knowledge. We were able to extract the landslide, the landslide-dammed lake and other lakes successfully from S1 imagery. However, the extraction of the class river course was not straightforward using S1 imagery, since there were several misclassifications between river course and shadow areas. Therefore, we used S2 imagery to extract the river course and the changes in the river course caused by the landslide.

The second objective of this study was to use different polarizations, i.e. $\mathrm{VV}$ and $\mathrm{VH}$, for change detection. In this research, the changed areas (landslide and landslide-dammed lake) are better detectable using the $\mathrm{VH}$ polarization. Thus, for this case study, VH polarisation can be a better candidate for extracting changes related to landslides and landslide-dammed lakes. The result of change analysis for $\mathrm{VV}$ polarization contained not only the changed areas, but also water bodies and vegetation. Therefore, the use of this polarisation for change detection should be handled with care. A more detailed investigation is needed to generalize this effect to other areas. This study showed the potential of using freely available EO imagery such as S1 and S2 images for analysing and studying natural hazards, such as large landslides, and their impacts.

\section{CONCLUSION}

SAR imagery provides unique products that can be used for emergency response, like in the case of landslide events (Casagli et al., 2016; Hölbling et al., 2012). We successfully mapped the landslide, the landslide-dammed lake and other lakes using S1 imagery within an OBIA framework. We also demonstrated that change detection using $\mathrm{VH}$ polarisation achieved a better result compared to change detection using VV polarization.

We also showed that OBIA is a suitable method to map the changes caused by landslides. Future work will focus on the transferability of the approach to the other area where landslides affect the rivers system.

\section{ACKNOWLEDGEMENTS}

This research has been supported by Austrian Science Fund (FWF) through the project MORPH (Mapping, monitoring and modelling the spatio-temporal dynamics of land surface morphology; FWF-P29461-N29) and the Doctoral College GIScience (DK W 1237-N23), and by the Austrian Academy of Sciences (ÖAW) through the project RiCoLa (Detection and analysis of landslide-induced river course changes and lake formation),

\section{REFERENCES}

Blaschke, T., Hay, G.J., Kelly, M., Lang, S., Hofmann, P., Addink, E., Queiroz Feitosa, R., van der Meer, F., van der Werff, H., van Coillie, F., Tiede, D., 2014. Geographic ObjectBased Image Analysis - Towards a new paradigm. ISPRS J. Photogramm. Remote Sens. 87, 180-191. https://doi.org/10.1016/J.ISPRSJPRS.2013.09.014

Casagli, N., Cigna, F., Bianchini, S., Hölbling, D., Füreder, P., Righini, G., Del Conte, S., Friedl, B., Schneiderbauer, S., Iasio, C., Vlcko, J., Greif, V., Proske, H., Granica, K., Falco, S., Lozzi, S., Mora, O., Arnaud, A., Novali, F., Bianchi, M., 2016. Landslide mapping and monitoring by using radar and optical remote sensing: Examples from the EC-FP7 project SAFER. Remote Sens. Appl. Soc. Environ. 4, 92-108. https://doi.org/10.1016/J.RSASE.2016.07.001

Chen, G., Weng, Q., Hay, G.J., He, Y., 2018. Geographic object-based image analysis (GEOBIA): emerging trends and future opportunities. GIScience Remote Sens. 55, 159-182. https://doi.org/10.1080/15481603.2018.1426092

Cigna, F., 2018. Observing geohazards from space. MDPI https://doi.org/https://doi.org/10.3390/books978-3-03842-776-6

Helgason, J.K., Sæmundssson, P., Drouin, V., Jóhannesson, T., 2019. The Hítardalur landslide in West Iceland in July 2018, in: EGU: Geophysical Research Abstracts. Vienna, Austria.

Hölbling, D., Eisank, C., Albrecht, F., Vecchiotti, F., Friedl, B., Weinke, E., Kociu, A., Hölbling, D., Eisank, C., Albrecht, F., Vecchiotti, F., Friedl, B., Weinke, E., Kociu, A., 2017. Comparing Manual and Semi-Automated Landslide Mapping Based on Optical Satellite Images from Different Sensors. Geosciences 7, 37. https://doi.org/10.3390/geosciences7020037 Hölbling, D., Friedl, B., Dittrich, J., Cigna, F., Pedersen, G., 2018. Combined interpretation of optical and SAR data for landslide mapping, in: Jemec Auflic, M., Mikos, M., Verbovsek, T. (Eds.), Advances in Landslide Research. Proceedings of the 3rd Regional Symposium on Landslides the Adriatic-Balkan Region. Ljubljana, Slovenia, pp. 11-13.

Hölbling, D., Füreder, P., Antolini, F., Cigna, F., Casagli, N., Lang, S., Hölbling, D., Füreder, P., Antolini, F., Cigna, F., Casagli, N., Lang, S., 2012. A Semi-Automated Object-Based Approach for Landslide Detection Validated by Persistent Scatterer Interferometry Measures and Landslide Inventories. Remote Sens. 4, 1310-1336. https://doi.org/10.3390/rs4051310

Jensen, J.R., 2015. Introductory Digital Image Processing: A Remote Sensing Perspective, 4th ed. Prentice Hall Press, Upper Saddle River, NJ, USA.

Jensen, J.R., 2009. Remote Sensing of the Environment: An Earth Resource Perspective, 2nd ed, Prentice Hall series in Geographic Information Science. Pearson Prentice Hall.

Jenson, J.R., 1983. Urban/Suburban Land Use Analysis, in: Colwell, R.N. (Ed.), Manual of Remote Sensing. American Society of Photogrammetry, Falls Church, Va., pp. 1571-1666.

Joyce, K.E., Belliss, S.E., Samsonov, S. V., McNeill, S.J., Glassey, P.J., 2009. A review of the status of satellite remote sensing and image processing techniques for mapping natural hazards and disasters. Prog. Phys. Geogr. Earth Environ. 33, 
183-207. https://doi.org/10.1177/0309133309339563

Lee, J.-S., Pottier, E., 2009. Polarimetric Radar Imaging: From basics to applications., Polarimetric Radar Imaging: From Basics to Applications. CRC press. https://doi.org/10.1201/9781420054989

Lu, D., Mausel, P., Brondízio, E., Moran, E., 2004. Change detection techniques. Int. J. Remote Sens. 25, 2365-2407. https://doi.org/10.1080/0143116031000139863

Pétursson, H., 2018. Large landslides since the middle of the last century.

Plank, S., Twele, A., Martinis, S., Plank, S., Twele, A., Martinis, S., 2016. Landslide Mapping in Vegetated Areas Using Change Detection Based on Optical and Polarimetric SAR Data. Remote Sens. 8, 307. https://doi.org/10.3390/rs8040307

Sæmundsson, P., Morino, C., Helgason, J.K., Conway, S.J., Pétursson, H.G., 2018. The triggering factors of the Móafellshyrna debris slide in northern Iceland: Intense precipitation, earthquake activity and thawing of mountain permafrost. Sci. Total Environ. 621, 1163-1175. https://doi.org/10.1016/J.SCITOTENV.2017.10.111

Singh, A., 1989. Review Article Digital change detection techniques using remotely-sensed data. Int. J. Remote Sens. 10, 989-1003. https://doi.org/10.1080/01431168908903939

Zuhlke, M., Fomferra, N., Brockmann, C., Peters, M., Veci, L., Malik, J., Regner, P., 2015. SNAP (Sentinel Application Platform) and the ESA Sentinel 3 Toolbox, in: Sentinel-3 for Science Workshop, ESA Special Publication. p. 21. 